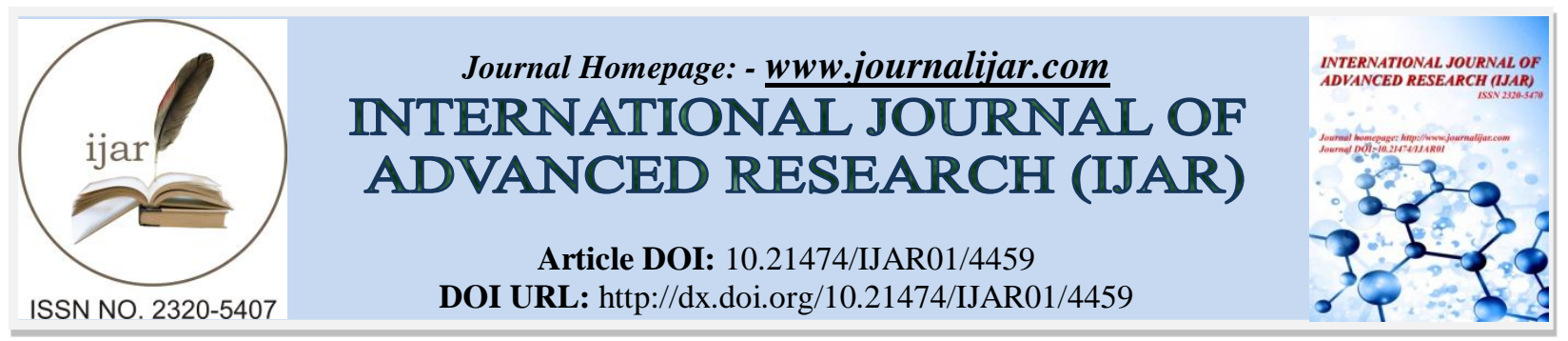

RESEARCH ARTICLE

\title{
ELECTROCARDIOGRAM PATTERN IN FEMALES SUFFERING FROM PREMENSTRUAL SYNDROME.
}

Jana Kamel Bashraheel ${ }^{1}$, Abdel Rahman Fahmy Ahmed Saba ${ }^{2}$ and Azra Kirmani ${ }^{3}$.

1. Master's degree, Faculty of Applied Medical Sciences, Medical Laboratory Technology Department, Kind Abdulaziz University.

2. of physiology Faculty of Medicine Ain shams.

3. from NTR University of Health Sciences.

\section{Manuscript Info}

\section{Manuscript History}

Received: 12 April 2017

Final Accepted: 14 May 2017

Published: June 2017

Key words:-

Females; Premenstrual syndrome; ECG

pattern; heart rate; Irritability;

Depression; Headache; Constipation.

\section{Abstract}

Background: Premenstrual syndrome (PMS) is a common but ill understood condition and has significant impact on the quality of life of the females. In attempted to increase the understanding of this condition. The aim of the work was to find out whether there is an identifiable ECG pattern during the premenstrual period in females suffering from PMS. Methods: 44 female in the reproductive age were selected. A twelve lead ECG (ELI 100) was used to make recordings for each subject twice for one month, once before the menstrual bleeding started and the other after the menstrual bleeding stopped. Height and Weight also was obtained, fill a questioner that included personal information such as: age, age of menarche, date of the last menstrual bleeding. According to symptoms the forty four students were subdivided into two main groups. The first group was the PMS group (34 subjects) and the second group was the control group (10 subjects). Results: Findings showed a statistically non significant difference in the mean heart rate in the pre-menstrual phase between the two groups. Irritability was the most common symptom of PMS, found in $94 \%$ of the subjects, depression and emotional liability in $79 \%$, bloating in $50 \%$, headache and decreased ability to concentrate in 38\%, constipation in 32\% and finally edema in $15 \%$ of the subjects. In conclusion there was no significant change in the heart rate as recorded on the ECG during the premenstrual period among subjects with PMS. There is no specific ECG pattern which can be identified during the PMS.

Copy Right, IJAR, 2017,. All rights reserved.

\section{Introduction:-}

Women of reproductive age sometimes suffer from symptoms during the late luteal phase of their menstrual cycle, and these complaints are collectively termed premenstrual syndrome .The premenstrual syndrome (PMS) is a combination of mental and physical symptoms that arise in the luteal phase of the menstrual cycle. After the onset of menstruation, the symptoms disappear. Nearly 300 different symptoms have been reported and, for most women, 
these symptoms are self-limited. However $15 \%$ of women with PMS have symptoms so severe that it requires medical intervention. ${ }^{(1)}$

PMS is a common (prevalence rate 3-30\%) ${ }^{(2)(3)}$ but ill understood condition as regards its etiology, diagnosis and treatment, which has significant impact on the quality of life of the females. This study has attempted to increase the understanding of this condition. It aimed to identify a specific ECG pattern during the PMS.

Previous studies have identified higher resting heart rate due to decreased parasympathetic and increased sympathetic activity during the pre menstrual phase among females with Premenstrual syndrome. ${ }^{(4,5)}$ Asessment of the prevalence of PMS among female medical students in Al-Ahsa, Saudi Arabia was done by a study.PMS was diagnosed in $35.6 \%$ of the cases. ${ }^{(6)}$ A study hypothesized that there are core symptoms that discriminate PMS women from non PMS women. The study concluded that there are six core symptoms that discriminate PMS women from non PMS women. These symptoms are mood swings, anxiety, aches, cramps, decreased interest in activities and food cravings. ${ }^{(7)}$

A relationship between PMS and hypertension has been suggested by a study. Four hundred and forty seven subjects were included in the study.61\% of these subjects have met the criteria of PMS. There was an increase in systolic and diastolic blood pressure in the early luteal phase of women with PMS. The study concluded that PMS might predict hypertension in the future of currently normotensive females. ${ }^{(8)}$

Another study compared a group of PMS with a group of healthy controls who had no PMS. Measurements of basal heart rate, systolic and diastolic blood pressure, respiratory rate and peripheral temperature were taken. The subjects the performed the 61 point relaxation technique. The parameters were then rerecorded .The study concluded that the 61 point relaxation technique reduced the sympathetic activity and reduced the high basal sympathetic tone in the PMS subjects due to stress. ${ }^{(9)}$

The hypotheses of finding an increase in heart rate and decrease in the PR interval during premenstrual syndrome due to decreased parasympathetic activity and altered autonomic function.

The aim of the work was to find out whether there is an identifiable ECG (electrocardiogram) pattern during the premenstrual period in females suffering from Premenstrual syndrome (PMS), which could help to understand PMS better.

\section{Study design and subjects:-}

The study was done in the research lab of physiology department, faculty of medicine, King Abdul-Aziz University. 44 female in the reproductive age were selected. All volunteers were consented. Subjects with psychiatric, mental diseases and epilepsies were not included in the study. A twelve lead ECG (ELI 100) was used to make recordings for each subject twice for one month, once before the menstrual bleeding started and the other after the menstrual bleeding stopped. ECG is the record of fluctuation potential that represents the algebraic sum of the action potentials of the myocardial fibers can be recorded from the surface of the body during the cardiac cycle.

An announcement was made in King Abdul-Aziz university inviting volunteers to participate. Before recording physical measurements were obtained from each volunteer including: height and Weight.

Each subject was asked to fill a questioner that included personal information such as: age, age of menarche, date of the last menstrual bleeding, marital state, history of child birth (if the subject is married), medications that are taken for PMS (if there are any) and symptoms of PMS that the subject suffers from.

Each subject was asked to sign a consent form that was approved by the human ethical committee. According to symptoms the forty four students were subdivided into two main groups. The first group was the PMS group (34 subjects) and the second group was the control group (10 subjects). The number of subjects in this study was justified based on sample size calculation (calculation of power). Electrodes Standard position: limb; R arm; L arm; $\mathrm{R}$ leg(earth); L leg healthy volunteers were divided into two groups (PMS- pre-menstrual symptoms and NPMSwithout pre-menstrual symptoms) of 32 volunteers each $(n=32)$. The heart rate was measured (among other variables) in the Pre-menstrual, menstrual, post-menstrual and ovulatory phases. Findings showed a statistically significant difference in the mean heart rate in the pre-menstrual phase between the two groups. 
The following table reproduced from the study shows a standard deviation (roughly equal in both groups) of about 7 in the Premenstrual phase. The difference in the mean heart rate between the two groups is about 6 .

\begin{tabular}{|l|l|l|l|l|}
\hline & Premenstrual & Menstrual & Postmenstrual & Ovulatory \\
\hline PMS & $90.91(7.11)$ & $89.53(5.91)$ & $81.75(7.26)$ & $89.03(7.13)$ \\
\hline NPMS & $85.28(7.01)$ & $87.34(7.53)$ & $83.78(7.09)$ & $85.84(9.46)$ \\
\hline
\end{tabular}

Results and Discussion:-

Table 1:-Various parameters obtained from the PMS Group.

\begin{tabular}{|c|c|c|c|c|c|c|c|c|}
\hline & $\begin{array}{l}\text { Heart rate (pre } \\
\text { menstrual) }\end{array}$ & $\begin{array}{l}\text { PR interval } \\
\text { (pre } \\
\text { menstrual) }\end{array}$ & $\begin{array}{l}\text { Heart rate } \\
\text { (post } \\
\text { menstrual) }\end{array}$ & $\begin{array}{l}\text { PR interval } \\
\text { (post } \\
\text { menstrual) }\end{array}$ & $\begin{array}{l}\text { Height in } \\
\mathrm{cm}\end{array}$ & weight & age & $\begin{array}{c}\text { Age of } \\
\text { menarche }\end{array}$ \\
\hline 1 & 80 & 0.136 & 69.767 & 0.154 & 158 & 48 & 25 & 15 \\
\hline 2 & 75.949 & 0.136 & 63.821 & 0.138 & 158 & 89 & 22 & 12 \\
\hline 3 & 54.05 & 0.134 & 71.428 & 0.154 & 164 & 53 & 22 & 14 \\
\hline 4 & 66.67 & 0.122 & 67.416 & 0.128 & 163 & 62 & 22 & 14 \\
\hline 5 & 95.238 & 0.14 & 78.947 & 0.148 & 160 & 52.5 & 22 & 12 \\
\hline 6 & 88.235 & 0.142 & 76.923 & 0.132 & 163 & 55 & 20 & 13 \\
\hline 7 & 61.856 & 0.14 & 52.632 & 0.134 & 158 & 47 & 26 & 16 \\
\hline 8 & 83.333 & 0.132 & 89.552 & 0.16 & 156 & 56 & 20 & 14 \\
\hline 9 & 92.308 & 0.176 & 75.949 & 0.166 & 155 & 68.4 & 19 & 13 \\
\hline 10 & 78.947 & 0.146 & 89.552 & 0.146 & 164 & 72 & 32 & 15 \\
\hline 11 & 89.552 & 0.138 & 90.909 & 0.154 & 147 & 38.4 & 23 & 15 \\
\hline 12 & 85.714 & 0.172 & 75.949 & 0.18 & 165 & 75 & 20 & 12 \\
\hline 13 & 88.235 & 0.154 & 83.333 & 0.144 & 152 & 51 & 20 & 13 \\
\hline 14 & 68.182 & 0.134 & 65.217 & 0.08 & 155 & 43 & 21 & 15 \\
\hline 15 & 78.947 & 0.124 & 67.416 & 0.12 & 163 & 50 & 20 & 12 \\
\hline 16 & 69.767 & 0.114 & 75 & 0.12 & 158 & 48 & 20 & 12 \\
\hline 17 & 75.949 & 0.12 & 71.428 & 0.164 & 153 & 53 & 23 & 12 \\
\hline 18 & 93.75 & 0.198 & 71.429 & 0.192 & 158 & 47.5 & 19 & 13 \\
\hline 19 & 84.507 & 0.13 & 56.604 & 0.136 & 165 & 100 & 20 & 12 \\
\hline 20 & 95.238 & 0.13 & 78.947 & 0.12 & 155 & 75 & 21 & 12 \\
\hline 21 & 70.588 & 0.148 & 76.923 & 0.148 & 154 & 46 & 21 & 12 \\
\hline 22 & 68.965 & 0.136 & 85.714 & 0.12 & 150 & 65 & 20 & 13 \\
\hline 23 & 88.235 & 0.132 & 84.507 & 0.128 & 160 & 75.8 & 21 & 13 \\
\hline 24 & 67.416 & 0.122 & 81.081 & 0.118 & 161 & 64 & 21 & 13 \\
\hline 25 & 70.588 & 0.12 & 83.333 & 0.154 & 170 & 64 & 20 & 13 \\
\hline 26 & 89.552 & 0.16 & 78.947 & 0.138 & 168.5 & 72.4 & 21 & 11 \\
\hline 27 & 65.217 & 0.114 & 57.143 & 0.1 & 165 & 54 & 22 & 13 \\
\hline 28 & 75 & 0.156 & 81.081 & 0.174 & 156 & 61 & 21 & 14 \\
\hline 29 & 78.947 & 0.174 & 65.217 & 0.17 & 150 & 56.5 & 23 & 11 \\
\hline 30 & 69.767 & 0.102 & 75.949 & 0.96 & 160 & 55 & 21 & 14 \\
\hline 31 & 45.455 & 0.146 & 57.143 & 0.14 & 160 & 60 & 20 & 12 \\
\hline 32 & 93.75 & 0.162 & 64.516 & 0.16 & 155 & 47 & 20 & 12 \\
\hline 33 & 86.957 & 0.16 & 76.923 & 0.158 & 157 & 57 & 21 & 13 \\
\hline 34 & 86.957 & 0.146 & 85.714 & 0.14 & 160 & 70 & 20 & 13 \\
\hline
\end{tabular}


Table 2:- Various parameters obtained from the non PMS Group (controls)

\begin{tabular}{|c|c|c|c|c|c|c|c|c|}
\hline & $\begin{array}{c}\text { Heart rate } \\
\text { (pre } \\
\text { menstrual) }\end{array}$ & $\begin{array}{c}\text { PR interval } \\
\text { (pre } \\
\text { menstrual) }\end{array}$ & $\begin{array}{c}\text { Heart rate } \\
\text { (post menstrual) }\end{array}$ & $\begin{array}{c}\text { PR interval } \\
\text { (post } \\
\text { menstrual) }\end{array}$ & height & $\begin{array}{c}\text { weigh } \\
\mathrm{t}\end{array}$ & age & $\begin{array}{c}\text { Age of } \\
\text { menarche }\end{array}$ \\
\hline 1 & 96.774 & 0.148 & 96.774 & 0.146 & 156 & 47.5 & 20 & 13 \\
\hline 2 & 75.949 & 0.15 & 65.217 & 0.14 & 163 & 69 & 19 & 12 \\
\hline 3 & 72.289 & 0.148 & 65.217 & 0.04 & 172.2 & 87 & 19 & 15 \\
\hline 4 & 66.667 & 0.144 & 78.947 & 0.168 & 154 & 56 & 19 & 11 \\
\hline 5 & 69.767 & 0.164 & 60.606 & 0.154 & 155 & 44.4 & 19 & 13 \\
\hline 6 & 63.829 & 0.116 & 73.171 & 0.114 & 165 & 49.5 & 22 & 11 \\
\hline 7 & 88.235 & 0.164 & 72.289 & 0.204 & 155 & 52 & 21 & 12 \\
\hline 8 & 67.416 & 0.138 & 93.75 & 0.132 & 151 & 67 & 45 & 13 \\
\hline 9 & 92.308 & 0.118 & 75 & 0.124 & 157 & 53 & 20 & 14 \\
\hline 10 & 74.074 & 0.128 & 85.714 & 0.144 & 156 & 50 & 19 & 13 \\
\hline
\end{tabular}

Table 3:- Distribution of symptoms among the PMS group.

\begin{tabular}{|c|c|c|c|c|c|c|c|c|}
\hline $\begin{array}{c}\text { Serial } \\
\text { number }\end{array}$ & headache & irritability & bloating & edema & $\begin{array}{c}\text { Emotional } \\
\text { liability }\end{array}$ & $\begin{array}{c}\text { Decreased } \\
\text { ability to } \\
\text { concentrate }\end{array}$ & depression & constipation \\
\hline 1 & - & + & + & + & + & + & + & + \\
\hline 2 & - & + & - & - & - & - & + & + \\
\hline 3 & + & + & - & - & + & - & + & + \\
\hline 4 & - & + & + & + & + & - & + & - \\
\hline 5 & + & + & + & + & + & + & + & + \\
\hline 6 & - & + & - & - & + & - & + & - \\
\hline 7 & - & - & - & - & + & - & - & - \\
\hline 8 & - & + & - & - & + & - & - & - \\
\hline 9 & + & + & - & - & - & - & - & - \\
\hline 10 & - & + & + & - & + & - & + & - \\
\hline 11 & + & + & + & - & + & + & + & + \\
\hline 12 & - & + & - & - & - & - & + & - \\
\hline 13 & - & + & - & - & + & + & + & - \\
\hline 14 & + & + & - & - & + & + & + & - \\
\hline 15 & + & + & + & - & + & + & - & + \\
\hline 16 & - & + & - & - & + & + & + & - \\
\hline 17 & + & + & - & - & + & - & + & - \\
\hline 18 & - & + & - & - & + & + & + & + \\
\hline 19 & + & + & - & - & + & - & + & - \\
\hline 20 & - & + & + & - & + & - & - & + \\
\hline 21 & - & + & + & - & - & + & + & - \\
\hline 22 & + & + & - & - & + & + & + & - \\
\hline 23 & + & + & - & - & - & - & - & - \\
\hline 24 & - & + & + & + & + & - & + & - \\
\hline 25 & - & + & + & - & + & - & + & - \\
\hline 26 & - & + & + & - & + & - & + & - \\
\hline 27 & - & + & - & - & - & - & + & - \\
\hline 28 & - & + & + & - & + & - & - & + \\
\hline 29 & - & + & + & - & + & + & + & + \\
\hline 30 & + & + & + & + & + & + & + & + \\
\hline 31 & + & + & + & - & + & + & + & - \\
\hline 32 & + & + & - & - & - & - & + & - \\
\hline 33 & - & - & + & - & + & - & + & - \\
\hline 34 & - & + & + & - & + & - & + & - \\
\hline
\end{tabular}


Table 4:- Results using the paired t test.

\begin{tabular}{|c|c|c|}
\hline & $\mathrm{P}$ value & Inference \\
\hline $\begin{array}{c}\text { Premenstrual HR } \\
\text { PMS vs Premenstrual HR ctl }\end{array}$ & 0.4927 & Not Significant \\
\hline $\begin{array}{c}\text { Postmenstrual HR } \\
\text { PMS vs Premenstrual HR ctl }\end{array}$ & 0.4615 & Not Significant \\
\hline $\begin{array}{c}\text { PMS HR } \\
\text { Premenstrual vs Postmenstrual }\end{array}$ & 0.1926 & Not Significant \\
\hline $\begin{array}{c}\text { Ctl HR } \\
\text { Premenstrual vs Postmenstrual }\end{array}$ & 0.6855 & Not Significant \\
\hline $\begin{array}{l}\text { PR interval-Premenstrual } \\
\text { PMS vs Ctl }\end{array}$ & 0.5466 & Not Significant \\
\hline $\begin{array}{c}\text { PR interval-Postmenstrual } \\
\text { PMS vs Ctl }\end{array}$ & 0.6080 & Not Significant \\
\hline $\begin{array}{c}\text { PR interval in PMS } \\
\text { Premenstrual vs Postmenstrual }\end{array}$ & 0.6080 & Not Significant \\
\hline $\begin{array}{c}\text { PR interval in Ctl } \\
\text { Premenstrual vs Postmenstrual }\end{array}$ & 0.6070 & Not Significant \\
\hline
\end{tabular}

\section{Figure (1): Age distribution among the PMS subjects}

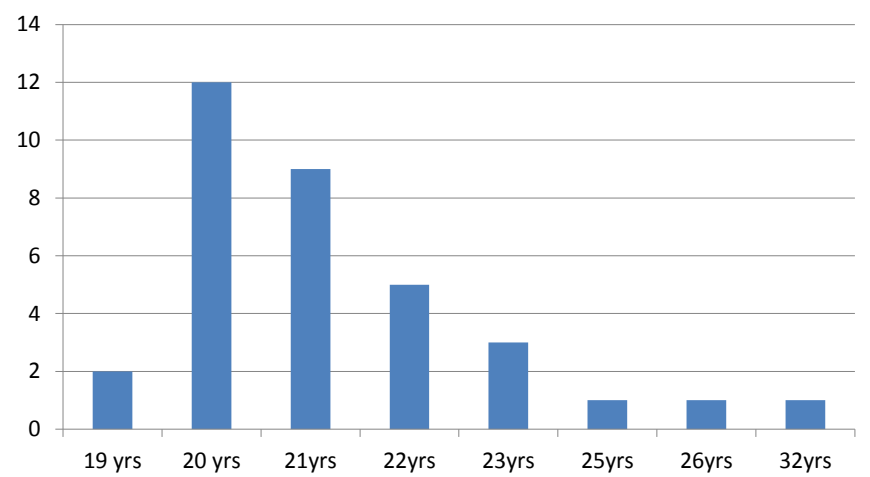

Figure (2): Age distribution among the Controls

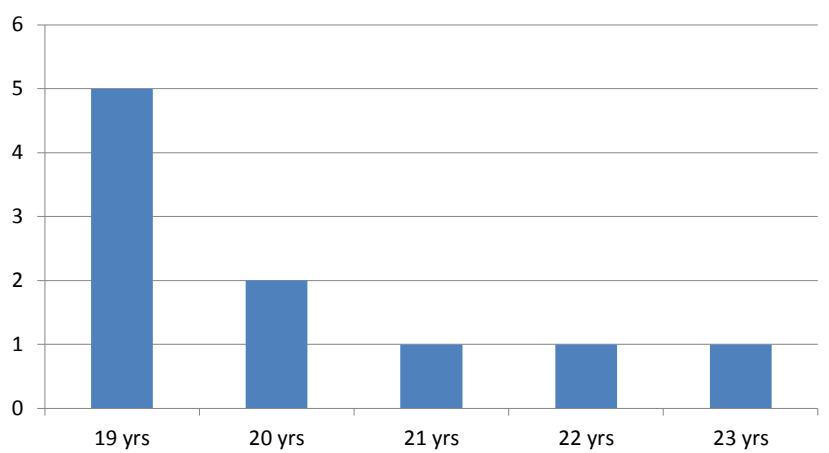




\section{Figure (3): Weight Distribution among the PMS}

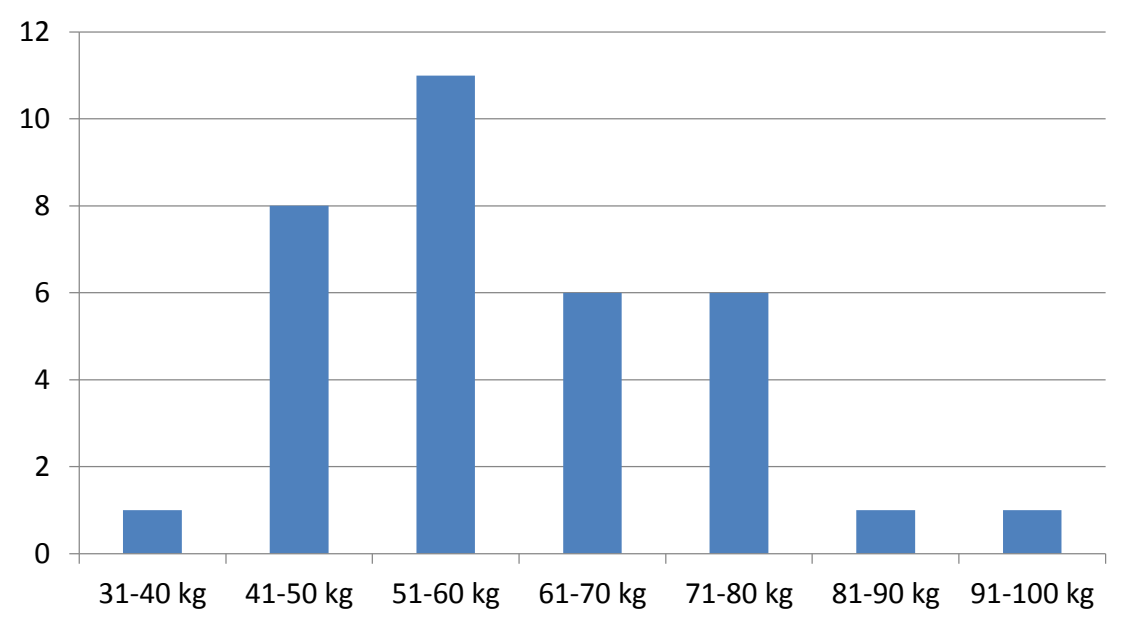

\section{Figure (4): Weight Distribution among the Controls}

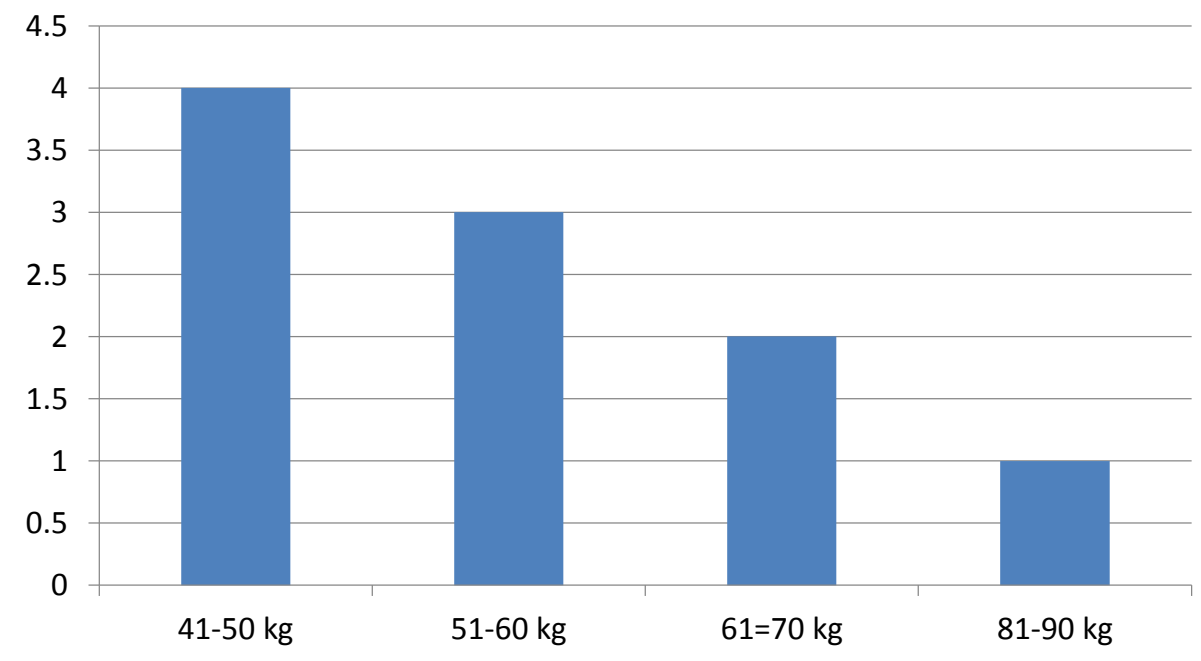


Figure (5): Age of Puberty among the PMS subjects.

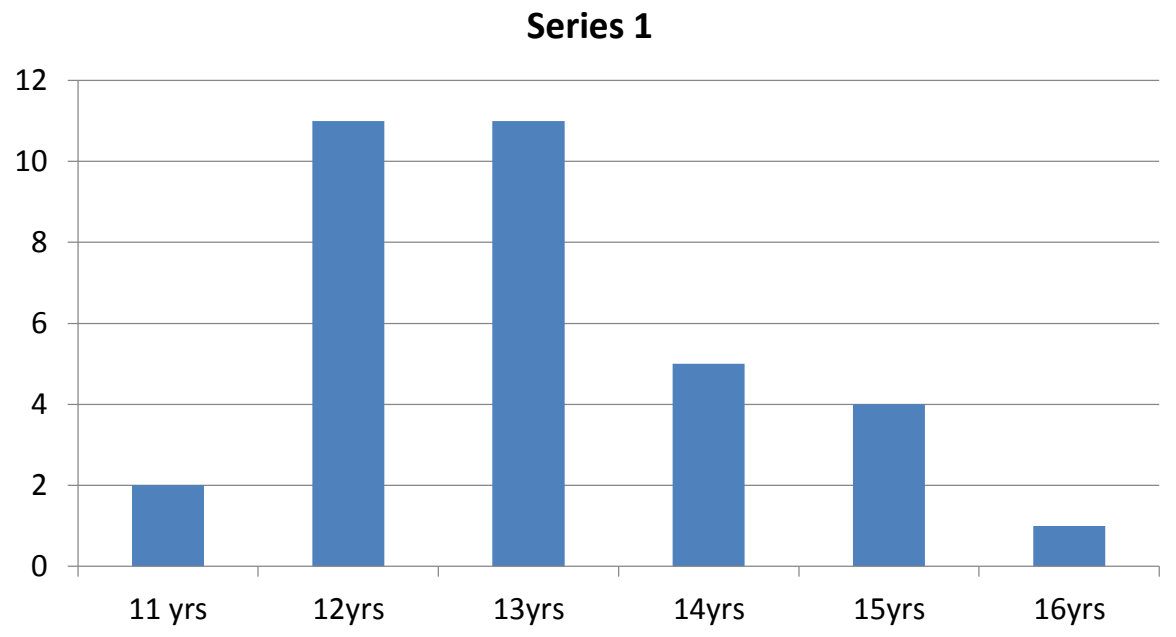

Figure (6): Age of Puberty among the Controls

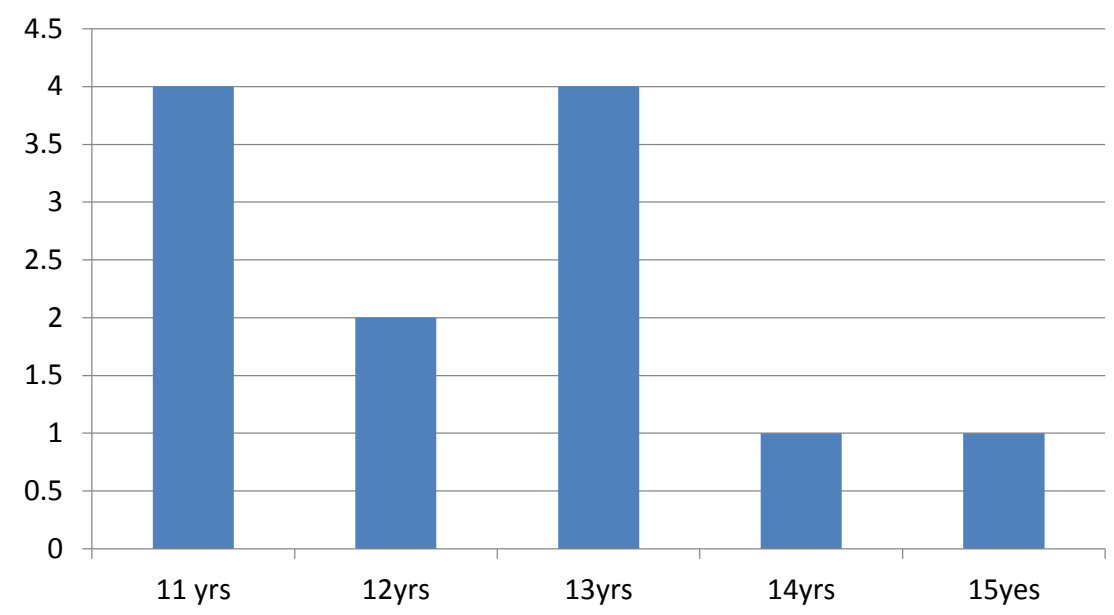




\section{Figure (7): Pre \& Post Menstrual Heart Rate among the PMS}

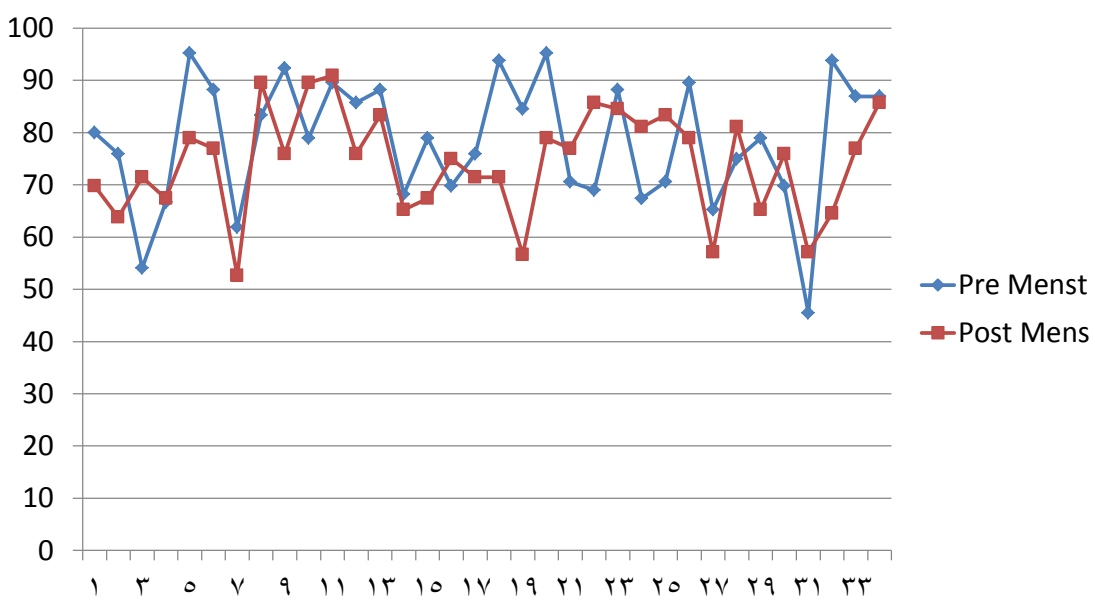

Figure (8): Pre \& Post Menstrual Heart Rate among the Controls

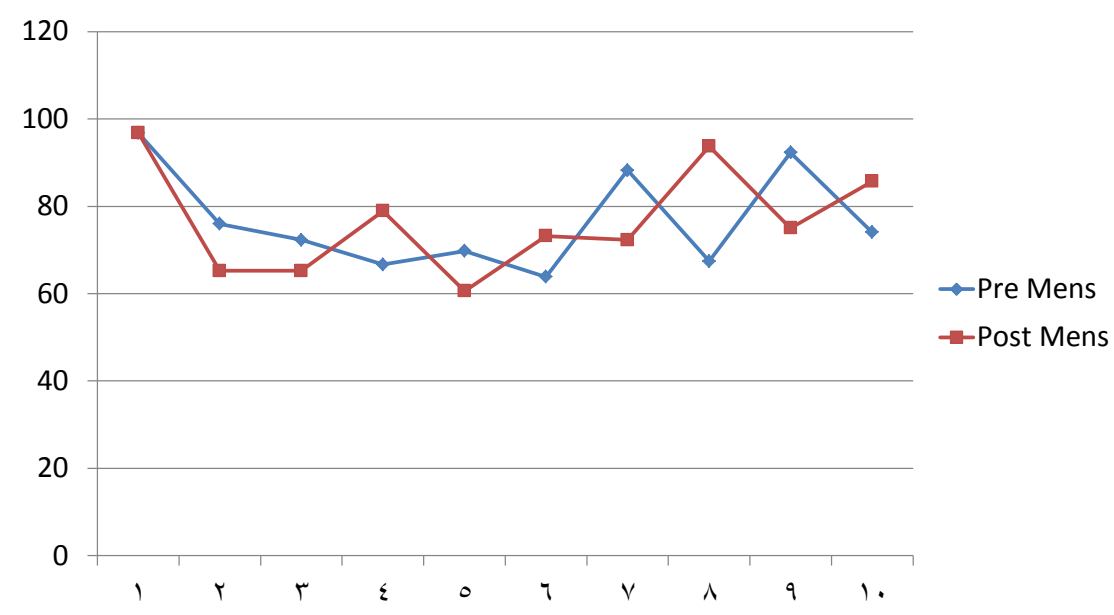


Figure (9): Pre \& Post Menstrual PR interval among the PMS

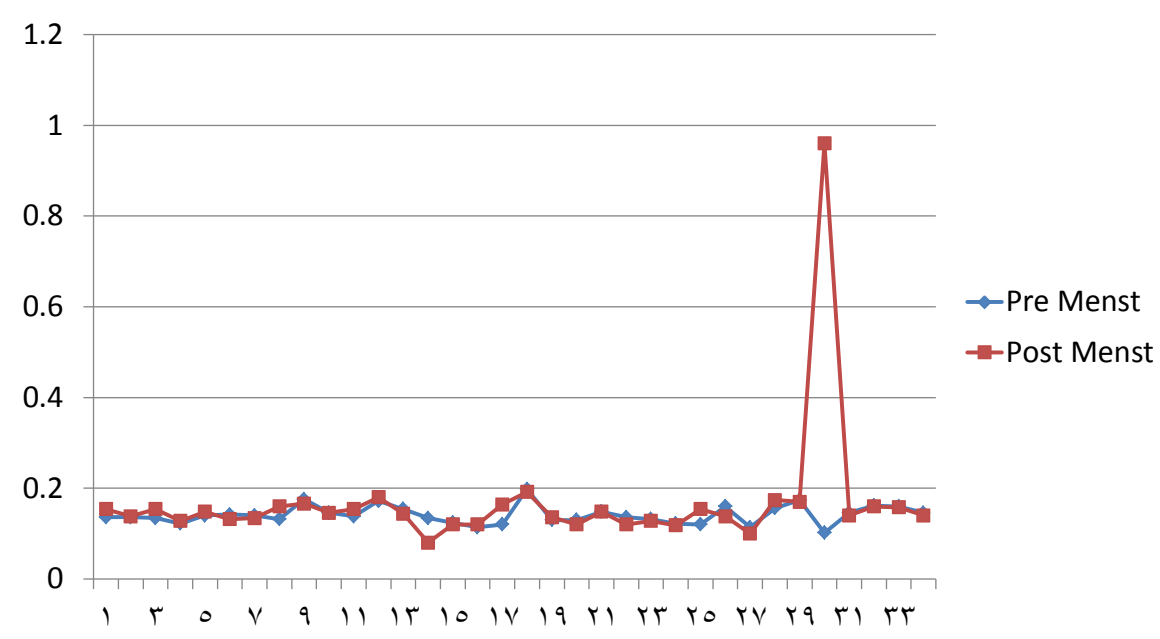

Figure (10): Pre \& Post Menstrual PR interval among the Controls

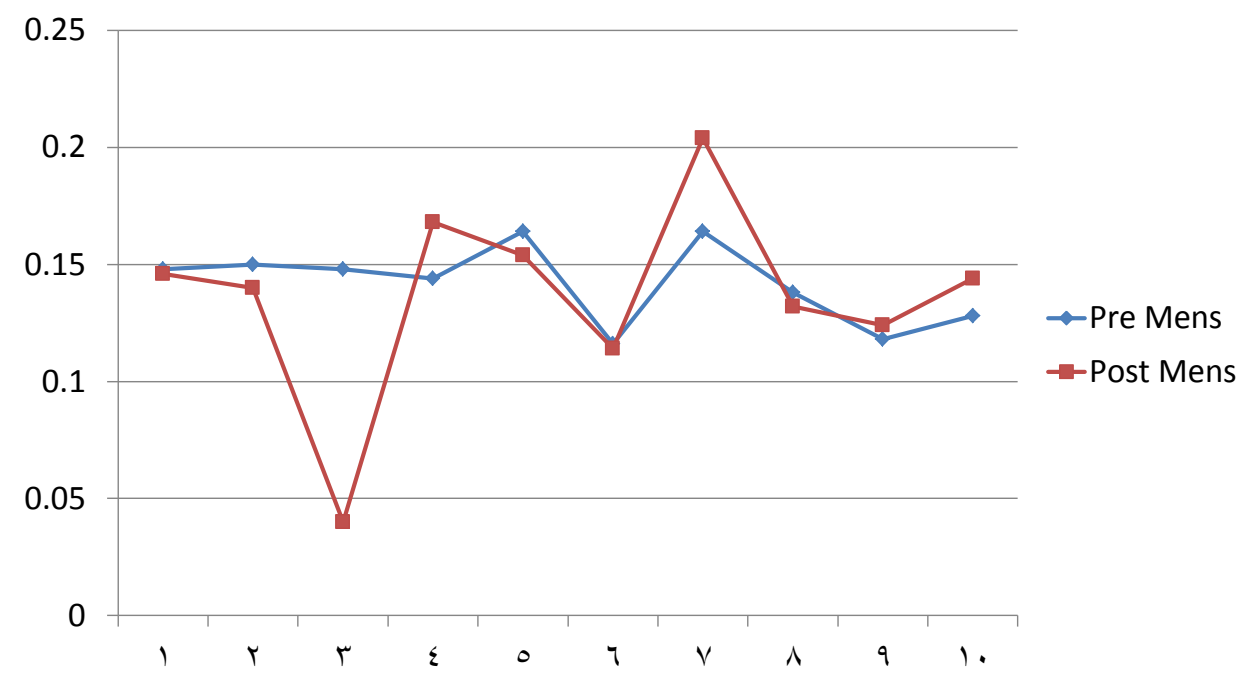


Figure 11:- Incidence of various symptoms among the PMS subjects.

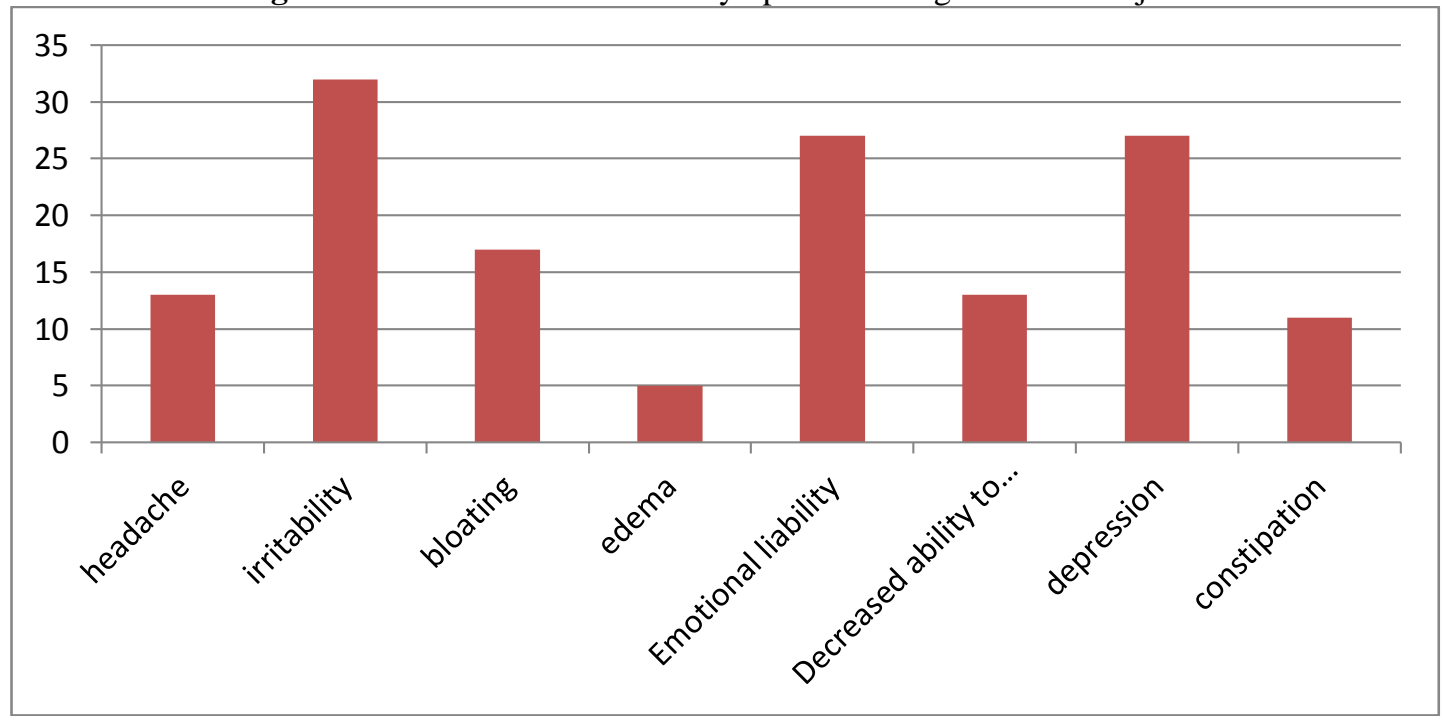

This study attempted to identify an ECG pattern if present during the premenstrual phase of females with premenstrual syndrome. The hypotheses of finding an increase in heart rate and decrease in the PR interval was based on the previous studies which identified an increase in heart rate during premenstrual syndrome, ${ }^{(10)},{ }^{(11)}$ decreased parasympathetic activity ${ }^{(12)(13)}$ altered autonomic function. ${ }^{(14)(15)(16)}$

Matsumoto et al. (2006), found decreased sympathovagal activity in all phases of the menstrual cycle in subjects with Pre Menstrual Dysphoric Disorder (PMDD). The same study also identified decreased heart rate variability in the premenstrual period among subjects with PMS. ${ }^{(17)}$

The changes in heart rate identified by earlier studies were not identified in this study. Out of the 34 females with PMS only one female had symptoms severe enough to warranty medication. Perhaps ECG recordings on females with more severe symptoms may yield results consistent with the earlier works. It is also possible that heart rate variability (HRV) if recorded in the same females may provide evidence of decreased parasympathetic activity as it is a more sensitive indicator.

Our results are consistent with results obtained by Ozisik HI (2005) who concluded that the sympathetic skin response was similar during the late luteal and follicular phases of both PMS subjects and non PMS subjects. ${ }^{(18)}$

This study identified irritability as the most common symptom where $94 \%$ of the PMS subjects suffered from irritability. The next common symptoms were depression and emotional liability with $79 \%$ of the PMS subjects. Then there was bloating with $50 \%$ of the subjects. After that there were headache and decreased ability to concentrate with $38 \%$ of the subjects suffering from them. Then comes constipation with $32 \%$ percentage and finally comes edema with only $15 \%$ of the subjects suffering from it.

\section{Conclusion and Recommendations:-}

In conclusion there was no significant change in the heart rate as recorded on the ECG during the premenstrual period among subjects with PMS. There is no specific ECG pattern which can be identified during the PMS. So considering the PMS patients, authors recommend to identifying the heart rate variability on the same subjects on whom we have performed ECG; ECG recording in subjects with more severe symptoms than the present group of females; Measurement of blood pressure during and after the premenstrual period in PMS which is expected to be higher during the premenstrual period; Recording of an EEG (electroencephalogram) pattern in PMS subjects; Measurement of endorphins in PMS which are expected to be low; 5-CT scan of the brain in PMS to identify significant edema; Vitamin D and calcium level measurement in subjects with PMS which are expected to be low; Effect of vitamin D supplementation in PMS subjects; Levels of monoamines in PMS subjects with various degrees of symptoms. 
Type a message...

\section{References:-}

1. Schorge,Schaffer,Halvorson,Hoffman,Bradshaw,Cunningham,Williams gynecology.

2. Dean BB, Borenstein JE, Knight K, Yonkers K (2006). "Evaluating the criteria used for identification of PMS". $J$ Womens Health (Larchmt).

3. Rapkin Obstet Gynecol(1987,1997)

4. Freeman EW. Expert Opin Pharmacother. (2010 Dec;11(17):2879-89. Epub 2010 Aug 5). Review.University of Pennsylvania, Departments of Obstetrics/Gynecology and Psychiatry, Philadelphia, Therapeutic management of premenstrual syndrome.

5. Landén M, Wennerblom B, Tygesen H, Modigh K, Sörvik K, Ysander C, Ekman A, Nissbrandt H, Olsson M, Eriksson E. Psychoneuroendocrinology. (2004 Jul;29(6):733-40).Section of Psychiatry, Institute of Clinical Neuroscience, Göteborg University, Gothenburg, Sweden.

6. Balaha MH, Abd El Monem Amr M, Saleh Al Moghannum M, Saab Al Muhaidab N.(2010 Apr 23;5:4).The phenomenology of premenstrual syndrome in female medical students: a cross sectional study.

7. Inoue Y. Terao T.,. Iwata N, Okamoto K., Kojima H. Okamoto T. Yoshimura R. and Nakamura J. .Psychopharmacology Volume 190, Number 2, 213-219, DOI: 10.1007/s00213-006-0607-Fluctuating serotonergic function in premenstrual dysphoric disorder and premenstrual syndrome: findings from neuroendocrine challenge tests.

8. Okeahialam BN, Obindo JT, Ogbonna C. (2008 Dec;37(4):361-7).Prevalence of premenstrual syndrome and its relationship with blood pressure in young adult females.

9. Dvivedi J, Dvivedi S, Mahajan KK, Mittal S, Singhal A.(2008 Jan-Mar;52(1):69-76).Effect of '61-points relaxation technique' on stress parameters in premenstrual syndrome.Department of Physiology, Himalayan Institute of Medical Sciences, Jolly Grant, Dehradun - 248140.

10. Bäckström T, Hammarbäck S.Ann..Med.( 1991 Dec;23(6):625-33). Department of Obstetrics, Gynecology and Physiology, University of Umeå, Sweden.Premenstrual syndrome--psychiatric or gynaecological disorder?

11. Ghanbari Z, Haghollahi F, Shariat M, Foroshani AR, Ashrafi M. Effects of calcium supplement therapy in women with premenstrual syndrome. Taiwan J Obstet Gynecol. (2009 Jun;48(2):124-9).ValiAsr Reproductive Health Research Center, Tehran University of Medical Sciences, Tehran, Iran.

12. Baker, Fiona C. PhD, ${ }^{1,3}$ Tracey L. Kahan, $\mathrm{PhD},{ }^{2} \mathrm{John}$ Trinder, $\mathrm{PhD},{ }^{4}$ and Ian M. Colrain, $\mathrm{PhD} \cdot(2007$ Oct;30(10):1283-91).Sleep quality and the sleep electroencephalogram in women with severe premenstrual syndrome.

13. Guyton and Hall,Textbook of medical physiology, $11^{\text {th }}$ edition

14. Indusekhar R, Usman SB, O'Brien S. (2006 Jan-Feb;15(1):57-69). Expert guidelines for the treatment of severe PMS, PMDD, and comorbidities: the role of SSRIs. Department of Psychiatry \& Behavioral Neurosciences, McMaster University, Women's Health Concerns Clinic, St. Joseph's Hospital, Hamilton, Ontario, Canada. Academic Unit, University Hospital of North Staffordshire.

15. Inoue Y. Terao T.,. Iwata N, Okamoto K., Kojima H. Okamoto T. Yoshimura R. and Nakamura J. .Psychopharmacology Volume 190, Number 2, 213-219, DOI: 10.1007/s00213-006-0607-Fluctuating serotonergic function in premenstrual dysphoric disorder and premenstrual syndrome: findings from neuroendocrine challenge tests.

16. Landén M, Wennerblom B, Tygesen H, Modigh K, Sörvik K, Ysander C, Ekman A, Nissbrandt H, Olsson M, Eriksson E. Psychoneuroendocrinology. (2004 Jul;29(6):733-40).Section of Psychiatry, Institute of Clinical Neuroscience, Göteborg University, Gothenburg, Sweden.

17. Matsumoto T, Ushiroyama T, Morimura M, Moritani T, Hayashi T, Suzuki T, Tatsumi NJ Psychosom Obstet Gynaecol. (2006 Sep;27(3):131-9)Autonomic nervous system activity in the late luteal phase of eumenorrheic women with premenstrual symptomatology.

18. Ozisik HI, Kamisli O, Karlidag R, Kizkin S, Ozcan C.Clin Auton Res. (2005 Jun;15(3):233-7) 